\title{
Biocompatibilidad de los adhesivos dentinarios
}

\author{
Paz Pumpido F*
}

\section{RESUMEN}

Se describe el proceso de aislamiento y posterior cultivo de los odontoblastos humanos, identificándolos por sus características fenotípicas y funcionales. Una vez identificados se procede la congelación de los mismos en nitrógeno líquido. Se preparan unos discos de cristal sobre los que se pincelan tres adhesivos dentinarios sobre los que se vierte una suspensión de odontoblastos en el medio de cultivo apropiado y se procede a su cultivo. Se estudian las características funcionales de lass células en cuanto a síntesis de DNA, actividad de la fosfatasa alcalina, síntesis de colágeno y formación de matriz.

Palabras clave: Biocompatibilidad, odontoblastos, adhesivos dentinarios.

\section{ABSTRACT}

This is a description of the isolation and cultivation of human odontoblasts, and their identification via phenotypic and functional characteristics. Once they have been identified they are frozen in liquid nitrogen. Glass discs are then prepared and three dentin adhesives are applied with a brush, and then a suspension of odontoblasts in a suitable cultivation is poured on and the culture is prepared. The functional characteristics of the cells are studied in terms of DNA synthesis, alkaline phosphate activity, collagen synthesis and matrix formation.

Key words: Biocompatibility, Odontoblasts Dentin adhesives

Aceptado para publicación: octubre 2003

* Profesor Asociado. Facultad de Medicina y Odontología. Santiado de Compostela.

Paz Pumpido F. Biocompatibilidad de adhesivos dentinarios. Av. Odontoestomatol 2005; 21-1: 339-345.

La preservación de la vitalidad pulpar y el reintegro de una pulpa lesionada a su función normal, son las premisas biológicas que deben regir todas las maniobras operatorias.

Actualmente, podemos considerar que una vez que se atraviesa la unión amelo-dentinaria se entra en la pulpa, ya que anatómica, fisiológica y embriológicamente son el mismo tejido. Razón por la cual, se denomina complejo dentino-pulpar.

Embriológicamente, ambos son de origen mesenquimático; anatómicamente, el odontoblasto se prolonga a través de la dentina en el interior de los túbu- los dentinarios y fisiológicamente, la pulpa elabora y calcifica durante toda la vida a la dentina, al mismo tiempo que es la responsable de la sensibilidad dentinaria y de los cambios metabólicos que en ella se producen.

La pulpa dentaria, es un tejido conjuntivo altamente diferenciado y organizado, ricamente inervado y vascularizado, responsable de la vitalidad del diente. La dentina, está constituida esencialmente por sustancia extracelular, formando una matriz colagenosa muy mineralizada, con túbulos en su interior, que forma el cuerpo del diente; es el órgano de sostén del esmalte y de recubrimiento de la pulpa dentaria. 
Los procesos odontoblásticos que están dentro de la dentina sirven para transmitir estímulos desde el tejido hasta la pulpa, y los odontoblastos reaccionan a estos impulso produciendo dentina terciaria o esclerótica intratubular.

Una lesión leve, produce solamente un aumento de la permeabilidad de los túbulos cortados, con o sin rotura de la membrana pulpodentinal entre la predentina y la capa odontoblástica. Si la lesión es más severa, la porción nuclear de los odontoblastos presenta cambios tales como la vacuolización y atrofia de la capa odontoblástica. Si el daño ha sido grave y de corta duración, estas reacciones se confinan a la zona de los túbulos afectados por el corte. Sin embargo, si la lesión es más severa y prolongada, los efectos se extienden dentro de la zona subodontoblástica o más allá de esos límites. Si aumenta la intensidad de la lesión, la zona de pulpa por debajo de la cavidad presenta infiltraciones celulares, cambios en la sustancia fundamental, trombosis y hemorragias.

Si un agente lesionante, tal como una droga cáustica o un material de obturación ácido, actúan solamente durante un corto período de tiempo, normalmente la pulpa y la dentina se recuperan. Generalmente, la porción del contenido intratubular se calcifica, formando una capa impermeable de dentina esclerosada que protege a la pulpa de ulteriores ataques. Los residuos odontoblásticos son reemplazados por nuevos odontoblastos de las células mesenquimatosas de reserva de la pulpa y se forma una nueva capa, más bien irregular, de dentina reparativa.

Es evidente, por lo tanto que el tratamiento adecuado a unos túbulos recién cortados en una acción iatrogénicas imperativo que sea el adecuado con unos materiales apropiados, ya que cualquier material que se use como obturador tendrá sus efectos sobre el tejido pulpar porque las extremidades de los odontoblastos que se han seccionado quedan en contacto con él o con el fluido dentinario que continuamente se escapa a través de ellos.

Es sabido, que a pesar de que los materiales restauradores deben cumplir unos requisitos físicos, químicos y biológicos. También, es cierto que no conta- mos todavía con un material que satisfaga la totalidad de los mismos para ser considerado ideal. Es fundamental, por consiguiente que en el momento de seleccionar un material restaurador que su compatibilidad biológica debe prevalecer sobre cualquier otra característica.

Los adhesivos, se emplean directamente sobre las estructuras dentarias, por lo que independientemente, de aspectos derivados de la técnica de restauración y de la selección del material, la presencia o no de efectos biológicos del adhesivo sobre el diente, debería de condicionar los resultados obtenidos. A este respecto, son escasos o poco precisos los estudios disponibles en la bibliografía sobre la biocompatibilidad de este tipo de materiales.

Considerando lo anteriormente expuesto, hemos desarrollado una línea de investigación basada en la valoración de la compatibilidad de materiales aplicables en Odontología. En este estudio, pretendemos evaluar los efectos de diversas resinas, actualmente disponibles en el mercado, sobre la célula más especializada de la estructura dental, el odontoblasto, y que como tal, debería de ser más susceptible a la acción de materiales como los adhesivos.

Se trata de simular, en lo posible, las condiciones del entorno biológico donde van a ser aplicados los materiales.

Los objetivos que se persiguen son:

1) La puesta a punto de la técnica de obtención de odontoblastos a partir del cultivo de células pulpares procedentes de humanos.

2) La puesta a punto y la utilización de los procedimientos analíticos necesarios para determinar la biocompatibilidad in vitro de los materiales ensayados.

Valorar la biocompatibilidad in vitro de los materiales ensayados, mediante ensayos de biocompatibilidad específica. Esto es, el estudio en cultivo de la respuesta de osteoblastos humanos frente al material; evaluando el efecto directo del material sobre la supervivencia y la funcionalidad celular: En el primer caso, mediante test de viabilidad celular. En el 
segundo caso, estudiando funciones celulares tales como la síntesis DNA y de colágeno, la actividad de la fosfatasa alcalina, y la formación de matriz mineralizada.

Debido a la inexistencia de estudios de biocompatibilidad específica de los materiales dentales se hace necesario obtener un cultivo de odontoblastos procedentes de dientes humanos, para obtener un cultivo de dichas células específicas procedimos a la consecución de piezas dentarias sanas procedente se pacientes a los que se les extrajeron fundamentalmente por motivos ortodónticos o de inclusión de las mismas.

Se establecen las pautas para conseguir el cultivo celular de odontoblastos así como para determinar de una forma fehaciente la identidad de las células aisladas, para lo cual se realiza un completo estudio de las mismas estudiando sus características morfológicas y sus funciones celulares específicas de forma que no quede duda de que las células aisladas son odontoblastos y no hay en el cultivo ningún otro tipo celular de los existentes en la pulpa que contaminen el mismo.

Las células se obtienen mediante la extracción de la pulpa de los especimenes obtenidos y se someten a una digestión enzimática diferencial hasta conseguir un pellet que contiene solamente las células odontoblásticas.

Dichas células fueron cultivadas en placas de poliestireno en una cantidad conocida y fueron cultivadas de forma controlada en un ambiente de esterilidad y en condiciones determinadas.

Se procedió a la identificación de fenotipo celular desde el punto de vista morfológico y funcional en el primer caso, la caracterización morfológica se determinó mediante técnicas de microscopía electrónica de barrido y de transmisión y en el segundo caso, las características funcionales se determinaron analizando la síntesis de enzimas mediante técnicas histoquímicas y bioquímicas para determinar la actividad de la fosfatasa alcalina y analizando la formación de colágeno intracelular con técnicas de electroforesis y por último se determinó la evolución de la matriz extracelular formada, mediante técnicas de micros-

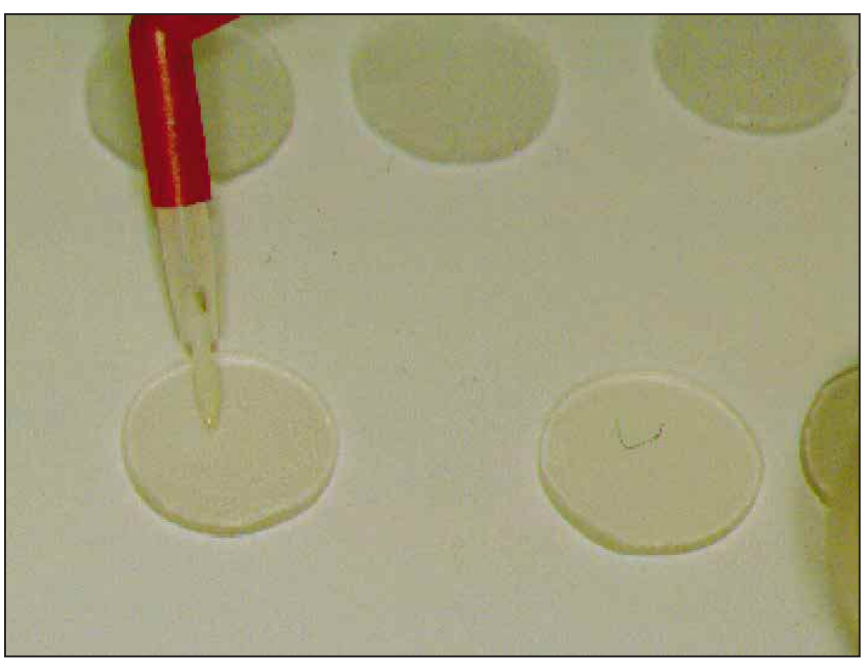

Fig. 1. Muestras

copía electrónica de barrido y espectrometría de dispersión de rayos $\mathrm{X}$.

Una vez establecido el fenotipo celular de los cultivos obtenidos se procede a la crioconservación de los mismos en nitrógeno líquido.

Para la realización de los ensayos de biocompatibilidad específica de los materiales a estudiar: adhesivos dentinarios de uso comercial, Syntac ${ }^{\circledR}$, Permagén ${ }^{\circledast}$ y Scotchbond Multipourpouse ${ }^{\circledR}$, se procedió a la aplicación de los mismos sobre discos de vidrio manufacturados de un $\mathrm{mm}$ de grosor y un $\mathrm{cm}$. de diámetro y sobre ellos se realizó la siembra de las células obtenidas caracterizadas fenotipicamente en placas microtitter de 24 pocillos y sobre el fondo de pocillo de poliestireno para utilizas estas ultimas como control (fig. 1).

En diferentes cronologías se obtuvieron muestras por triplicado para estudiar los siguientes parámetros: viabilidad celular y funcionalidad celular.

Se presenta un estudio estadístico de los resultados obtenidos y la microscopía electrónica de barrido y de transmisión.

\begin{tabular}{|c|c|c|c|}
\hline \multicolumn{4}{|c|}{ TABLA 1.- TEST DE VIABILIDAD } \\
\hline Control & Syntac $^{\oplus}$ & Permagén $^{\circledast}$ & Scotchbond .MP $^{\circledast}$ \\
\hline $87 \%$ & $87,3 \%$ & $84,5 \%$ & $83 \%$ \\
\hline
\end{tabular}




\section{Test de viabilidad celular}

Estos test, permiten evaluar la supervivencia celular en el momento del ensayo, ya que ofrecen información instantánea mediante métodos colorimétricos o contajes de radioactividad. Son particularmente útiles para valorar el efecto del material ensayado sobre la integridad de la membrana celular.

Nosotros, en este estudio, hemos evaluado la viabilidad celular mediante la técnica de exclusión con azul tripán; efectuando, mediante un hemocitómetro, el recuento de las células no teñidas, vivas, frente al total.

Siguiendo el protocolo descrito anteriormente, hemos podido comprobar que la viabilidad de las células en cultivo se veía afectada por la presencia de determinados adhesivos, con respecto al control.

El estudio de viabilidad aporto unas cifras de supervivencia del $87 \%$ para el control de poliestireno frente al $87,3 \%, 84,5 \%$ y $83 \%$ del Syntac ${ }^{\circledast}$, el Permagen ${ }^{\circledast}$ y el Scotchbond $M P^{\circledR}$.

\section{Síntensis de DNA}

Nosotros, en este ensayo utilizamos como índice de síntesis del DNA y por consiguiente, de la actividad proliferativa, el test de la incorporación de timidina tritiada. Para ello, mantuvimos a los odontoblastos sobre los discos de cristal con los diferentes adhesivos dentinarios o sobre el fondo de pocillo, como control, durante 48 horas para posteriormente añadir la timidina y cultivar 24 horas más, permitiendo de este modo su incorporación.

En nuestro estudio, hemos observado que la incorporación de timidina por parte de los odontoblastos, como índice de actividad proliferativa, es influida de forma significativa por la presencia de los diferentes sistemas adhesivos ensayados. Los niveles de incorporación de timidina tritiada fueron significativamente mayores $(p<0,01)$ en el Syntac ${ }^{\circledast}$ con respecto al control, y significativamente menores en Permagen ${ }^{\circledast}$ $(p<0,01)$ y en el Scotchbond ${ }^{\circledast} M P(p<0,01)$ con respecto al control (Tablas 2 y 3 ).

Nuestros resultados indican que algunos de los sis-

TABLA 2.- VALORES INDIVIDUIALES (C.P.M.), CORRESPONDIENTES A LA INCORPORACIÓN DE TIMIDINA TRITIADA, COMO ÍNDICE DE ACTIVIDAD PROLIFERATIVA, POR LOS ODONTOBLASTOS HUMANOS MANTENIDOS EN CULTIVO

\begin{tabular}{|c|c|c|c|}
\hline CONTROL & SYNTAC $^{\circledR}$ & PERMAGÉN $^{\circledR}$ & SCOTCHBOND $^{\circledR}$.MP $^{\text {MP }}$ \\
\hline $11.147,80$ & $13.266,75$ & $3.499,25$ & $7.383,76$ \\
\hline $11.362,05$ & $30.046,01$ & $3.415,00$ & $7.868,01$ \\
\hline $11.516,30$ & $31.347,01$ & $3.681,00$ & $7.878,51$ \\
\hline
\end{tabular}

TABLA 3.- INCORPORACIÓN DE TIMIDINA TRITIADA (VALORES MEDIOS EN C.P.M.) POR LOS ODONTOBLASTOS HUMANOS MANTENIDOS EN CULTIVO

\begin{tabular}{|c|c|c|c|}
\hline CONTROL & SYNTAC $^{\circledast}$ & PERMAGÉN $^{\circledR}$ & SCOTCHBOND $^{\circledR}$. MP $^{*}$ \\
\hline $11.342,05^{*}$ & $24.886,59 \pm 13.254,4^{*}$ & $3.531,75 \pm 266^{* *}$ & $7.710,12 \pm 494,75^{* *}$ \\
\hline
\end{tabular}

Se expresan los valores medios de tres mediciones por muestra, en intervalos de 12 horas. * diferencias significativas $(p<0,01)$ con respecto al Syntac $^{\circledast *}$ * diferencias significativas $(\mathrm{p}<0,01)$ con respecto al control.

TABLA 4.- ACTIVIDAD DE LA FOSFATASA ALCALINA, VALORES MEDIOS ( \pm DE); DE LOS ODONTOBLASTOS HUMANOS CULTIVADOS SOBRE SISTEMAS ADHESIVOS

\begin{tabular}{|c|c|c|c|}
\hline CONTROL & SYNTAC $^{\oplus}$ & PERMAGÉN $^{\circledR}$ & SCOTCHBOND $^{\circledR}$. MP $^{*}$ \\
\hline $2,34 \pm 0,56$ & $1,98 \pm 0,28^{*}$ & $0,97 \pm 0,15^{* *}$ & $0,64 \pm 0,23 * *$ \\
\hline
\end{tabular}

* diferencias significativas $(\mathrm{p}<0,01)$ con respecto al Syntac ${ }^{\oplus} *$ diferencias significativas $(\mathrm{p}<0,01)$ con respecto al control. 
temas adhesivos ensayados afectan negativamente a la funcionalidad de los odontoblastos en cultivo; disminuyendo la actividad proliferativa de dichas células en cultivo directo sobre los mismos.

\section{Actividad de la fosfatasa alcalina}

Una vez demostrada la expresión de la actividad de esta enzima, que en condiciones basales de cultivo es compatible con la de odontoblastos, se pretende verificar si dicha actividad es modificada por la presencia de los sistemas adhesivos empleados.

En nuestro estudio, hemos comprobado que la expresión de la fosfatasa alcalina es significativamente inferior $(p<0,01)$ en el Permagen y el MP con respecto al Syntac ${ }^{\circledR}$ y a los controles (Tabla 4). Esto es, tanto el Permagen ${ }^{\circledast}$ como el $\mathrm{MP}^{\circledR}$, afectan negativamente a la funcionalidad celular.

En relación con el Syntac ${ }^{\circledR}$, se ha comprobado que la actividad de la fosfatasa alcalina es inferior con respecto a los controles, aunque no de forma significativa. Consecuentemente, podemos afirmar que el Syntac no repercute negativamente sobre la funcionalidad celular de los odontoblastos.

\section{Síntesis de colágeno}

Como test de biocompatibilidad específica, mediante esta prueba de funcionalidad celular se pretende comprobar si sistemas de adhesión como el Syntac ${ }^{\circledast}$,

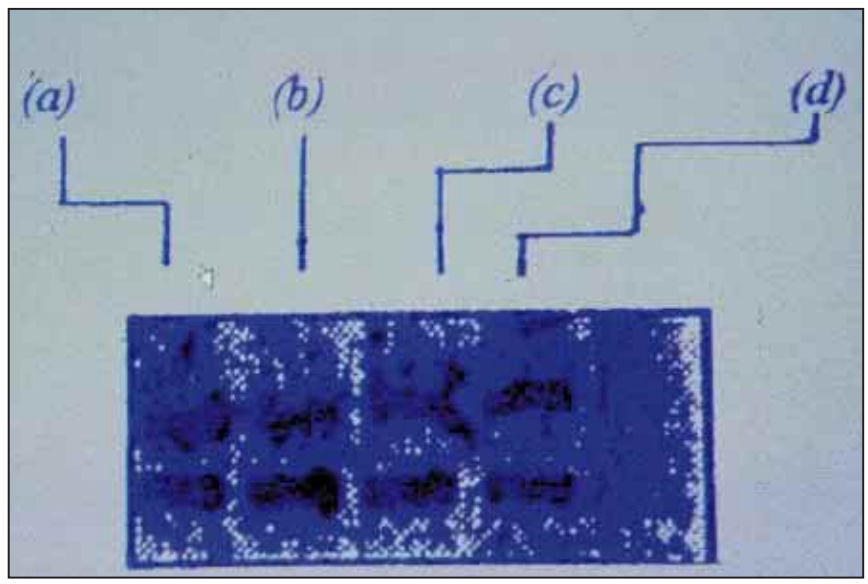

Fig. 2. Síntesis de colágeno. el $M P^{\circledR}$, y el Permagen ${ }^{\circledR}$, habitualmente empleados en odontología conservadora, afectan a las células con las que entran en contacto in vivo, los odontoblastos. Por ello, hemos cultivado odontoblastos sobre los sistemas referidos y sobre controles, sin material.

Los hallazgos que se derivan de este ensayo se muestran en la figura siguiente: (fig. 2).

Las bandas de colágeno corresponden de izquierda a derecha al control, al Syntac ${ }^{\circledast}$, al Permagen ${ }^{\circledast}$ y al $M P^{\circledast}$. Se observa como, siguiendo este orden, el espesor de las bandas detectadas disminuye. La síntesis de colágeno es inferior en los sistemas adhesivos que en los controles. Entre los sistemas adhesivos, se comprueba como la presencia de colágeno es inferior en el caso del Permagen ${ }^{\circledast}$ y el $M P^{\circledR}$ que en el caso del Syntac".

\section{FORMACIÓN DE MATRIZ CALCIFICADA}

\section{Microscopía electrónica de barrido}

Tomando como referencia tanto las imágenes de dientes extraídos como las de los cultivos controles, hemos valorado la repercusión de los distintos materiales ensayados sobre la formación de matriz extracelular.

La formación de matriz extracelular ha adoptado un patrón morfológico y cronológico completamente diferente entre los distintos materiales (fig. 3).

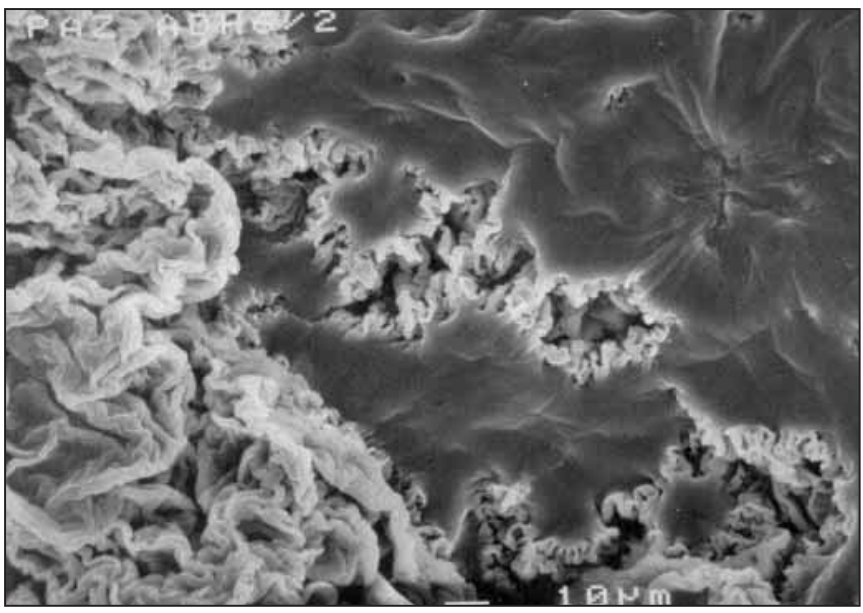

Fig. 3. Formación de matriz extracelular. 


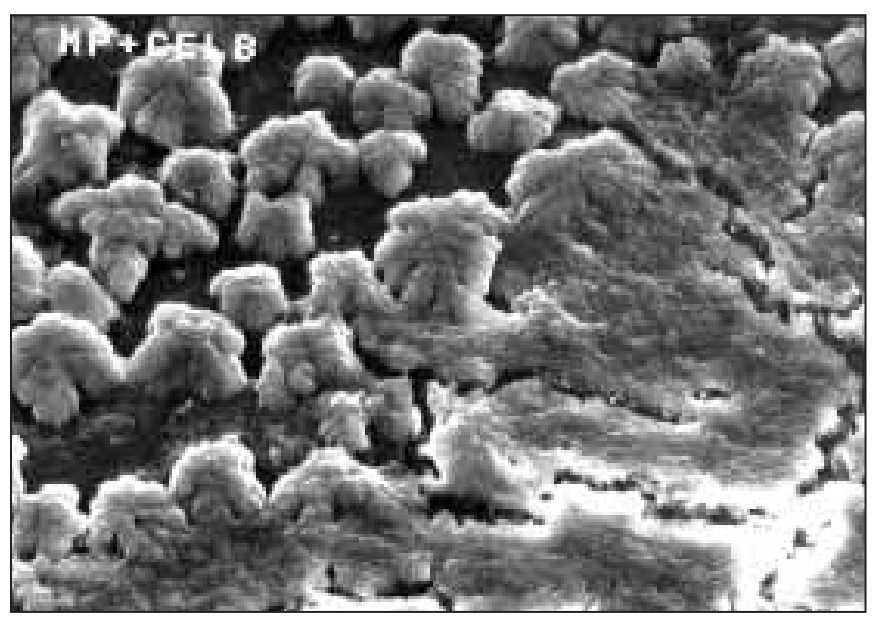

Fig. 4. Patrón de mineralización globular y mixto de la dentina.

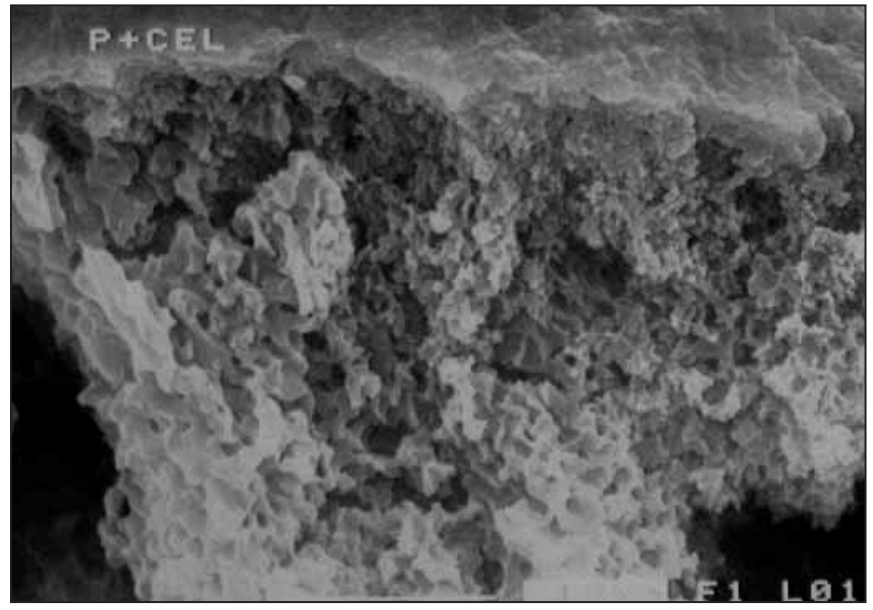

Fig. 5. Formación de matriz colágena y mineralizada.

En el Syntac ${ }^{\circledast}$ y en el $M P^{\circledR}$, ya a partir de las 5 semanas de cultivo se obtienen imágenes similares a las de los controles. Contrariamente a lo que sucede con el Permagen ${ }^{\circledR}$

Se forma una matriz, de colágeno tipo I (como se demuestra con anterioridad), que bajo microscopia electrónica ofrece un aspecto abollonado; creemos que se debe a que engloba en su interior a las células que la han formado, recubriéndolas. En relación con el $M \mathrm{MP}^{\circledR}$, de detectan formaciones que al igual que en los casos controles recuerda el patrón de mineralización globular y mixto de la dentina (fig. 4).

No obstante, y pese a las diferencias encontradas entre los sistemas citados, cabe reseñar que la formación de matriz colágena y mineralizada se verificó de forma solapada y continuada a lo largo del ensayo en todos los adhesivos (fig. 5).

Ello, condujo a la formación de una capa de gran espesor, con diferente grado de mineralización, sobre los discos de materiales

\section{Espectrofotometría de dispersión de rayos $\mathrm{x}$}

La utilización de esta técnica, nos ha permitido comprobar la variación en el contenido de calcio de la matriz extracelular formada por las células en cultivo, sobre los diferentes materiales ensayados. De esta manera, podemos valorar en que medida afectan estos materiales a la capacidad formadora de matriz, mineralizada o no, por parte de las células. Este ensayo, es de gran importancia en tanto que si alguno de los materiales favoreciese la formación de matriz sería óptimo para la aplicación en clínica. Contrariamente, si se alterar o disminuye la capacidad formadora de matriz extracelular, debería de replantearse su utilización en clínica .

Es sabido que los componentes que integran los sistemas adhesivos tienen capacidad de difundir a través de la dentina (Hanks et al., 1992). Por tanto, una vez introducido en una cavidad, tendrán una repercusión directa y/o indirecta sobre las células que están en su proximidad, los odontoblastos.

\begin{tabular}{|l|c|c|c|}
\hline \multicolumn{4}{|c|}{ TABLA 5.- CONCENTRACIONES DE CALCIO EN LA MATRIZ SINTETIZADA POR LOS } \\
ODONTOBLASTOS CULTIVADOS SOBRE LOS DIFERENTES SISTEMAS ADHESIVOS \\
\hline & SYNTAC $^{\star}$ & PERMAGÉ & SCOTCHBOND $^{\circledR} \cdot$ MP $^{\circ}$ \\
\hline 5 semanas & $02,02 \pm 1,08$ & $01,22 \pm 0,82$ & $01,19 \pm 1,36$ \\
\hline 4 meses & $11,67 \pm 0,25$ & $03,20 \pm 1,28^{*}$ & $02,93 \pm 0,72^{*}$ \\
\hline 7 meses & $26,84 \pm 3,60$ & $11,45 \pm 1,98^{*}$ & $11,84 \pm 0,59^{*}$ \\
\hline
\end{tabular}

Se expresan los valores medios de tres mediciones por muestra. * diferencias significativas $(\mathrm{p}<0,01)$ con respecto al control. 
En nuestro estudio, hemos comprobado que la proporción de calcio se incrementa de forma progresiva a los largo del tiempo de estudio, desde las 5 semanas a los 7 meses, en la matriz formada sobre los sistemas adhesivos ensayados. Es decir, que la matriz formada adquiere un carácter más mineralizado a lo largo del tiempo de cultivo.

No obstante, hemos comprobado que existen diferencias significativas entre los diferentes sistemas ensayados (Tabla 5).

El grado de mineralización de la matriz formada, estimado por la determinación del calcio en los cultivos, nos demuestra que es significativamente superior en el Syntac ${ }^{\circledR}$.

Los otros sistemas adhesivos, el Permagen ${ }^{\circledR}$ y el $M \mathrm{MP}^{\circledR}$, presentan unas cifras de calcio significativamente inferiores $(p<0,01)$.

Este hallazgo, conjuntamente con los anteriores, nos demuestra que el Syntac ${ }^{\circledast}$ es el sistema adhesivo más biocompatible de los ensayados. Es más, si consideramos nuestros resultados extrapolables a condiciones in vitro, el Syntac ${ }^{\circledR}$ podría no solo carecer de efectos tóxicos si no favorecer la formación de tejido mineralizado tras la restauración de la cavidad.

\section{CONCLUSIONES}

- La síntesis de DNA, como índice de actividad proliferativa

- Es significativamente mayor en los cultivos de odontoblastos sobre Syntac ${ }^{\circledR}$ en relación al control.

- La mayor actividad sobre Syntac ${ }^{\circledR}$ se atribuye a la estructura reticular que presenta el material.

- No existen diferencias significativas en la actividad enzimática específica de la fosfatasa alcalina entre cultivos de odontoblastos sobre Syntac ${ }^{\circledR}$ y el control .

- La actividad enzimática de la fosfatasa alcalina es significativamente menor en el Permagen ${ }^{\circledast}$ y el $\mathrm{SBMP}^{\circledR}$ con respecto al control.

- A lo largo del período de cultivo se forma matriz colágena y mineralizada en todos los cultivos sobre los adhesivos ensayados.

- La matriz formada sobre los cultivos se compone de colágeno tipo I y estructuras cristalinas fosfato cálcicas propias de la dentina en condiciones "in vivo".

- El Syntac ${ }^{\circledast}$ es el único, de los sistemas adhesivos ensayados que presenta características de biocompatibilidad " in vitro" en todos los parámetros 